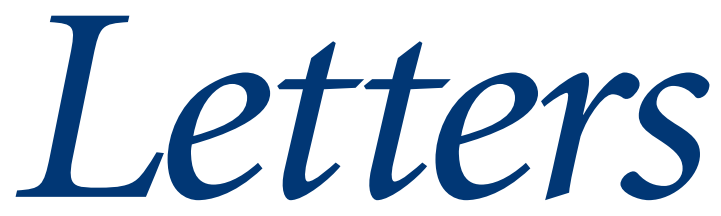

All letters are subject to editing and may be shortened. Letters should be sent to the BJGP office by e-mail in the first instance, addressed to

journal@rcgp.org.uk (please include your postal address). Alternatively, they may be sent by post as an MS Word or plain text version on CD or DVD. We regret that we cannot notify authors regarding publication. Letters not published in the Journal may be posted online on our Discussion Forum. For instructions please visit: http://www.rcgp.org.uk/bjgp-discuss

\section{Copying referral letters}

As a retired GP and a current user of NHS services as a patient with multiple sclerosis, I would like to highlight an example of what, in my opinion, appears to be continued bad practice in many, if not most, areas of the medical profession.

When I asked for a copy of a letter from my consultant it was peppered with inaccuracies. Some of these were fundamental, which I was able to rectify. But my main concern is: why is copying letters to patients not routine practice (taking into account issues of consent, confidentiality, and unexpected content)? From the literature and discussions with former colleagues, there appear to be four main reasons for not doing so.

One is that patients would not understand what is written about them because of the use of medical terminology. Yet in my experience as a doctor and a patient, the vast majority of what passes as medical terminology is just jargon. On the occasions when medical terms have to be used, a plain English definition can be included either in the letter or in a separate glossary. Also, content not covered in the consultation should be clearly marked as such. Writing in plain English should be the norm - I thoroughly recommend a guide published by the Plain English Campaign. ${ }^{1}$

A second argument is that not all patients want copies of letters. ${ }^{2}$ However, studies have shown that patients appreciate and find written communication helpful. ${ }^{3}$ I also strongly suspect that many more patients would wish to have copies of letters if they could actually understand them, particularly if they knew the letters might not address their agenda.

Third, there is an argument that copying letters to patients merely adds to bureaucracy and workloads. However, the extra work and expense in a hospital setting have been shown to be minimal. ${ }^{4}$ I cannot deny, that for GPs whose patients have easy access initially the workload will increase. But I argue that once patients and doctors have got used to this method of communication, this will improve. Unfortunately, I could find no studies looking at this issue in a general practice setting.

Lastly, there is a fear that more written communication would lead to an increase in complaints. The experience of former colleagues is that this is a true and valid reason. However, I argue that correct, clear, well-written letters, highlighting the patient's agenda and associated worries would reduce complaints to a minimum. Again, I could find no studies looking at this issue.

In my opinion, fear of litigation is not a valid reason. And if only to avoid the discomfort and inconvenience of having their poor letters pointed out by their patients, health professionals would write clearer and better correspondence, and so provide a better service.

Writing letters which patients understand and sending them copies would, in my opinion, also:

- help patients to be knowledgeable about their own health and, therefore, make the doctor's job easier;

- empower not only patients, but also doctors;

- remind them of what happened and what was decided in the consultation;

- give them a feeling of ownership and involvement in their care;
- help embed trust between patients and those caring for their health;

- enhance patients' existing rights to access their medical records;

- enable the patient to spot mistakes, such as medicine dosage errors; and

- perhaps be seen as another tool to add to doctors' skills of good communication.

In April 2003, the Department of Health set out good practice guidelines on 'Copying letters to Patients'. ${ }^{5}$ I commend these sensible and practical guidelines. Unfortunately, it appears they are not being widely followed. Why not?

\section{Mark Thornber,}

Merryorchard, Rumbling Bridge,

Kinross KY13 OPX

E-mail: markymark@ukgateway.net

\section{REFERENCES}

1. The Plain English Campaign, 2001 http://www.plainenglish.co.uk/medicalguide.pdf (accessed 6 Oct 2009).

2. Morrow G, Robson A, Harrington B, Haining S. A qualitative study to investigate why patients accept or decline a copy of their referral letter from their GP. Br J Gen Pract 2005; 55(517): 626-629.

3. Rao M, Fogarty P. What did the doctor say? J Obstet Gynaecol 2007; 27(5): 479-480.

4. Boaden R, Harris C. Copying letters to patients will it happen? Fam Pract 2005; 22(2): 141-143

5. Department of Health. Copying letters to patients: good practice guidelines. Department of Health, 2003. http://www.dh.gov.uk/en/Publicationsandstatistics/Pu blications/PublicationsPolicyAndGuidance/DH_4007 561 (accessed 6 Oct 2009).

DOI: 10.3399/bjgp09X472926

\section{Therapy for psychiatric therapy}

The September themed issue of the BJGP leads with Professor Dowrick saying the mainstays of GPs 
management are prescription of medication and referral for psychological therapy. ${ }^{1}$ Having trained in the 1980s we were taught our main strength in managing psychological distress was being there to listen. It was considered a core tool and skill. There is considerable debate about the value of both medication and talking therapy in mild or moderate psychological sadness, so it is a shame this basic asset of a GP is ignored or given no weight of value.

Related to this is the trend now for all sorts of diseases to be 'scored'. In my view, this may distract from the consultation and rarely gives information that is not obtained by normal history taking. In other diseases, such as rheumatoid arthritis, this scoring seems now to be the only outcome of outpatient reviews and highly potent medication is given on that score, not a holistic picture of the patient.

Can we be allowed to practice listening medicine even if we sacrifice QOF points as a result?

\section{John Sharvill,}

Balmoral, Deal, Kent CT14 7EQ.

E-mail: john.sharvill@nhs.net

\section{REFERENCE}

1. Dowrick C. Reasons to be cheerful? Reflections on GPs' responses to depression. Br J Gen Pract 2009; 59(566): 636-637.

DOI: 10.3399/bjgp09X472935

\section{Child and adolescent psychiatry liaison in Ireland}

I am writing from Ireland and have been a GP for the past 12 years; practising for 9 years in Ireland. I did my general practice training in the UK and so have worked in a multidisciplinary setting. However, this is a new phenomenon in Ireland and those that have trained in Ireland find this a difficult concept to grasp.
There is a real fear that their input into patient care will become diluted and undermined. Having trained in the UK, I find it bemusing that this concept is difficult to comprehend. However, it is a positive move as the needs of the patients are becoming complex and well dealt with in a multidisciplinary way.

My letter was inspired after reading the paper on 'GPs' role in the detection of psychological problems of young people." Unfortunately, GPs are finding it difficult to deal with these problems as most of the older teenagers come from unstable family environments and have been in care. The liaison between GPs and the child and adolescent psychiatry team is also not good and each side is suspicious of the other.

I do believe that those of us that have trained in the UK system can contribute positively to overcome these 'suspicions', as working together will keep these patients engaged with health professionals. This will provide a better environment for our young people when they need access to health professionals.

I have to thank the authors for an excellent article and would like to say that they contribute greatly to GPs here in Ireland that want to encourage a multidisciplinary ethos into general practice.

\section{Patricia Black,}

The Surgery, Patrick Street, Mountrath,

County Laois, Ireland.

E-mail: patricias.black@hotmail.com

\section{REFERENCE}

1. Mauerhofer A, Berchtold A, Michaud PA, Suris JC. GPs' role in the detection of psychological problems of young people: a population-based study. $\mathrm{Br} \mathrm{J} \mathrm{Gen}$ Pract 2009; 59(566): e308-314.

DOI: 10.3399/bjgp09X472944

\section{Crisis in the NHS}

I refer to the article by Edin Lakasing and Heather Francis ${ }^{1}$ - may I congratulate you on publishing it.

The article should be compulsory reading for all policy makers in the
Department of Health and for every member of the RCGP and BMA. It is eloquent, accurate, and painfully honest in the way it lays the problems bare. If either of the authors were to stand for election they would have my vote.

\section{Pallavi Devulapalli,} Forest Lodge, The Warren, Shouldham, King's Lynn, Norfolk PE33 ODQ. E-mail: freebird@doctors.org.uk

\section{REFERENCE}

1. Lakasing E, Francis H. Bureaucracy in general practice: time to halt a proliferating malaise. $\mathrm{Br} \mathrm{J} \mathrm{Gen}$ Pract 2009; 59(566): 696-698.

DOI: 10.3399/bjgp09X472953 